\title{
Comparative Assessment of the Effects of Two Methods of Pressure Support Adjustment on Respiratory Distress in Patients under Mechanical Ventilation Admitted to Intensive Care Units
}

\author{
Pooneh Barati ${ }^{1} \odot$, Somayeh Ghafari ${ }^{2} \odot$, Mahmood Saghaei $^{3} \odot$
}

\begin{abstract}
Background: Incorrect adjustment of the respiratory parameters of the mechanical ventilator increases respiratory distress and work of breathing (WOB) in mechanically ventilated patients. The accurate adjustment of pressure support increases the patient's comfort and decreases respiratory distress and WOB, etc.; thus, the present study was conducted to compare the effects of two pressure support adjustment methods on respiratory distress in patients under mechanical ventilation to investigate whether the rapid shallow breathing index (RSBI) method can reduce patients' respiratory distress more and faster than the tidal volume (VT) and respiratory rate (RR) methods.

Patients and methods: The study was conducted in 2020 on 56 mechanically ventilated patients with respiratory distress. The patients'respiratory distress was first measured using RSBI and the respiratory distress observation scale (RDOS). The pressure support was then adjusted in the patients according to the RSBI (in the trial group, $n=33$ ) and VT and RR (in the control group, $n=23$ ). The patients' respiratory distress was measured again in both groups 15 and 30 minutes after the pressure support adjustment.

Results: The results showed no significant differences between the two groups in the mean RSBI and RDOS before $(p=0.374, p=0.657$ respectively) and 30 ( $p=0.103, p=0.218$ respectively) minutes after the adjustment of the pressure support, but these mean values differed significantly ( $p=0.025$ for RSBI and $p=0.044$ for RDOS) between the groups 15 minutes after the adjustment. Moreover, the interaction effect of the group * time for RDOS has become significant nonlinearly $(p=0.037)$, but none of the interaction effects of the group * time were significant for RSBI (linear: $p=0.531$; nonlinear: $p=0.272$ ).

Conclusion: These two methods finally reduced the patients' respiratory distress almost equally, but RSBI method can relieve the patients' respiratory distress faster than the VT and RR methods.

Keywords: Intensive care unit, Mechanical ventilation, Pressure support, Respiratory distress.

Key message:VT, RR, and RSBI methods finally reduced the patients'respiratory distress almost equally, but RSBI method can relieve the patients' respiratory distress faster than the VT and RR methods.

Indian Journal of Critical Care Medicine (2021): 10.5005/jp-journals-10071-23960
\end{abstract}

\section{INTRODUCTION}

The use of a mechanical ventilator, especially a prolonged use, leads to several complications, such as respiratory distress. ${ }^{1-3}$ Respiratory distress denotes a disruption in patients' breathing, resulting in an increase in their work of breathing (WOB). Respiratory distress leads to patient's discomfort, the increased use of sedatives, etc., and it is, therefore, highly beneficial to identify and apply the factors contributing to a lower respiratory distress in the patients, such as ensuring the accurate adjustment of the respiratory parameters, to reduce the costs and the duration of intensive care unit (ICU) stay. ${ }^{3-6}$

Pressure support is one of the respiratory parameters of mechanical ventilation that provides a certain pressure during inhalation to support the patient's spontaneous breathing..$^{7-9}$ The most accurate pressure support adjustment method is monitoring the WOB. WOB is measured by invasive techniques that are not available in ICUs; therefore, the respiratory indices could probably predict the patients' WOB to adjust the pressure support. ${ }^{10}$ For this reason, in ICUs, pressure support is adjusted in a way so as to reduce the respiratory rate (RR) to less than 30 per minute and increase the tidal volume (VT) to $4-8 \mathrm{~mL} / \mathrm{kg}$. The only discussed adjustment
${ }^{1}$ Critical Care Nursing, Nursing and Midwifery Care Research Center, Faculty of Nursing and Midwifery, Isfahan University of Medical Sciences, Isfahan, Iran

${ }^{2}$ Nursing and Midwifery Care Research Center, Faculty of Nursing and Midwifery, Isfahan University of Medical Sciences, Isfahan, Iran

${ }^{3}$ Department of Anesthesia, Isfahan University of Medical Sciences, Isfahan, Iran. Anesthesiology and Critical Care Research Center, Isfahan University of Medical Sciences, Isfahan, Iran

Corresponding Author: Somayeh Ghafari, Nursing and Midwifery Care Research Center, Faculty of Nursing and Midwifery, Isfahan University of Medical Sciences, Isfahan, Iran, Phone: +98 9177108588, e-mail: somayehghafari@nm.mui.ac.ir; ghafari_somayeh@yahoo.com

How to cite this article: Barati P, Ghafari S, Saghaei M. Comparative Assessment of the Effects of Two Methods of Pressure Support Adjustment on Respiratory Distress in Patients under Mechanical Ventilation Admitted to Intensive Care Units. Indian J Crit Care Med 2021;25(9):1026-1030.

Source of Support: Isfahan University of Medical Sciences paid for Master of Science thesis of critical care nursing.

Conflict of interest: None

() Jaypee Brothers Medical Publishers. 2021 Open Access This article is distributed under the terms of the Creative Commons Attribution 4.0 International License (https://creativecommons.org/licenses/by-nc/4.0/), which permits unrestricted use, distribution, and non-commercial reproduction in any medium, provided you give appropriate credit to the original author(s) and the source, provide a link to the Creative Commons license, and indicate if changes were made. The Creative Commons Public Domain Dedication waiver (http://creativecommons.org/publicdomain/zero/1.0/) applies to the data made available in this article, unless otherwise stated. 
technique in articles and references is also the patient's RR and $\mathrm{VT}^{3,11-16}$ which is apparently not the most appropriate noninvasive method of adjusting pressure support, because the correlation of WOB with the RR and VT separately is less than its correlation with rapid shallow breathing index (RSBI). ${ }^{17}$ In RSBI, VT and RR are merged, and the number obtained from this index examines the depth and the number of breaths at the same time, and values exceeding 105 breaths per minute per liter indicate respiratory distress in the patients; ${ }^{18}$ as a result, according to the results of a study, WOB is more correlated with RSBI than with VT and $\mathrm{RR}^{17}$ and any parameter or index that is more correlated with WOB (as the most accurate invasive method of pressure support setting) is probably a more accurate noninvasive method for adjusting pressure support, and it may reduce patient's respiratory distress more and faster. ${ }^{19}$

Few studies have been done to determine the most accurate pressure support adjustment method. ${ }^{9,10,17,20}$ Further research is, therefore, necessary in this field. Thus, the present study was conducted to compare the effects of VT and RR and RSBI adjustment methods on respiratory distress in mechanically ventilated patients in ICUs.

\section{Patients and Methods}

This two-group and three-stage clinical trial was conducted in ICUs in 2020. The study objectives were explained to the patients' companions, and those who wished their patients to participate in the study signed the informed consent form. The study inclusion criteria were: Being an adult, treatment with pressure support ventilation, no chronic obstructive pulmonary disease, no acute respiratory distress syndrome, ${ }^{21,22}$ the number of breaths exceeding 30 per minute, VT $<4$ to $8 \mathrm{~mL} / \mathrm{kg}, \mathrm{RSBI}>105$ breaths $/ \mathrm{min} / \mathrm{L}$, respiratory distress observation scale (RDOS) score $>3$, and receiving no neuromuscular relaxants. ${ }^{5}$ The study exclusion criteria were: The patient's transfer to other wards or hospitals while adjusting the pressure support, or cardiac arrest or hemodynamic instability in the patients.

Firstly, a three-part questionnaire was completed by the researcher for each patient who participated in the study. The first part dealt with background information, including age, gender, Acute Physiology and Chronic Health Evaluation (APACHE) IV score, etc. The second and third parts examined the RSBI and RDOS scores of the patients. The APACHE IV score was determined by an ICU specialist (research collaborator).

The initial sampling was carried out by the simple nonrandom method. The participants were then divided into two groups by the ICU specialist (research collaborator) through random allocation; thus, patients' details were input into the minimization software and included age, gender, body mass index (BMI), use of analgesics and sedatives, APACHE IV score, and positive end-expiratory pressure (PEEP). Based on the results provided by this software, 23 patients were assigned to the control group and 33 patients to the trial group. Minimization software is a method for randomization of samples, and while randomizing, it distributes confounding variables, which were input into the minimization software, between the two groups in such a way that the two groups have the least difference in terms of these variables. Pressure support was then adjusted by the ICU specialist (research collaborator); it was adjusted according to the VT and RR in the control group RSBI in the trial group. Pressure support was adjusted such that the RR was $<30 /$ minute and the VT was $4-8 \mathrm{~mL} / \mathrm{kg}$ in the first group, and RSBI was $<105$ breaths $/ \mathrm{min} / \mathrm{L}$ in the second group. In this study, in both groups, at the beginning, the pressure support level was increased by 2 centimeter of water, and then, VT, RR, and other criteria mentioned in the questionnaire were monitored. If the patient was suffering from respiratory distress yet and needed more pressure support, then the pressure support was increased by 2 centimeter of water again, and this process continued until the patient's respiratory distress resolved; the maximum allowable pressure support level was 25 centimeter of water. RSBI and RDOS were measured again by the researcher 15 and 30 minutes after adjusting the pressure support. The reason for measuring respiratory signs at 15 -minute intervals was that in a study conducted by Aliverti et al., the effect of four levels of pressure support on the respiratory signs and indices was measured at 15-minute intervals. ${ }^{19}$ The present study was conducted in a double-blind format, since the researcher who examined the patients' respiratory distress and participating patients had no knowledge of the pressure support adjustment method used.

The RDOS has been used in different studies, and its reliability has been confirmed with Cronbach's alpha of $0.64 ., 23$ Once sampling ended, data were analyzed in SPSS-22. Flowchart 1-CONSORT flow diagram shows the process of inclusion of the patients.

\section{Results}

Table 1 presents the demographic and clinical details of the patients participating in the trial and control groups. The Chi-squared test and independent $t$-test showed no significant differences between the two groups in terms of the demographic and clinical details $(p>0.05)$. The independent $t$-test results showed no significant differences between the two groups in the mean RSBI and RDOS before ( $p=0.374$ and $p=0.657$, respectively) and 30 minutes ( $p=0.103$ and $p=0.218$, respectively) after the adjustment of the pressure support, but the difference between the groups in the mean RSBI and RDOS was statistically significant ( $p=0.025$ and $p=0.044$, respectively) 15 minutes after the adjustment (Table 2). Table 3 and 4 show the comparison of the mean of RDOS and RSBI between the groups at three times; based on the results of the repeated measure analysis of variance test, the interaction effect of group * time for RDOS has become significant nonlinearly $(p=0.037)$, but none of the interaction effects of the time *group for RSBI were significant (linear: $p=0.531$; nonlinear: $p=0.272$ ). The lowest and highest adjusted pressure supports in both groups were 12 and $24 \mathrm{~cm} \mathrm{H}_{2} \mathrm{O}$, respectively, and none of the patients in the study needed the maximum allowable pressure support $\left(25 \mathrm{~cm} \mathrm{H}_{2} \mathrm{O}\right)$ to relieve their respiratory distress symptoms.

\section{Discussion}

Although the most accurate method of pressure support adjustment is the invasive measurement of WOB, this method is not used in ICUs due to the lack of equipment for measuring WOB; thus, one of the medical challenges in patients treated with pressure support ventilation is finding the most accurate noninvasive method of pressure support adjustment that can reduce patients' respiratory distress more and fast. The study question was to investigate whether the RSBI method can reduce patients' respiratory distress more and faster than the VT and RR methods. The present findings suggest that 15 minutes after adjusting the pressure support, the mean RDOS and RSBI of the patients reduce further in the RSBI group compared to the VT and RR group. Moreover, the results showed no difference between the two groups in terms of the mean RSBI and RDOS 30 minutes 
Flowchart 1: CONSORT flow diagram

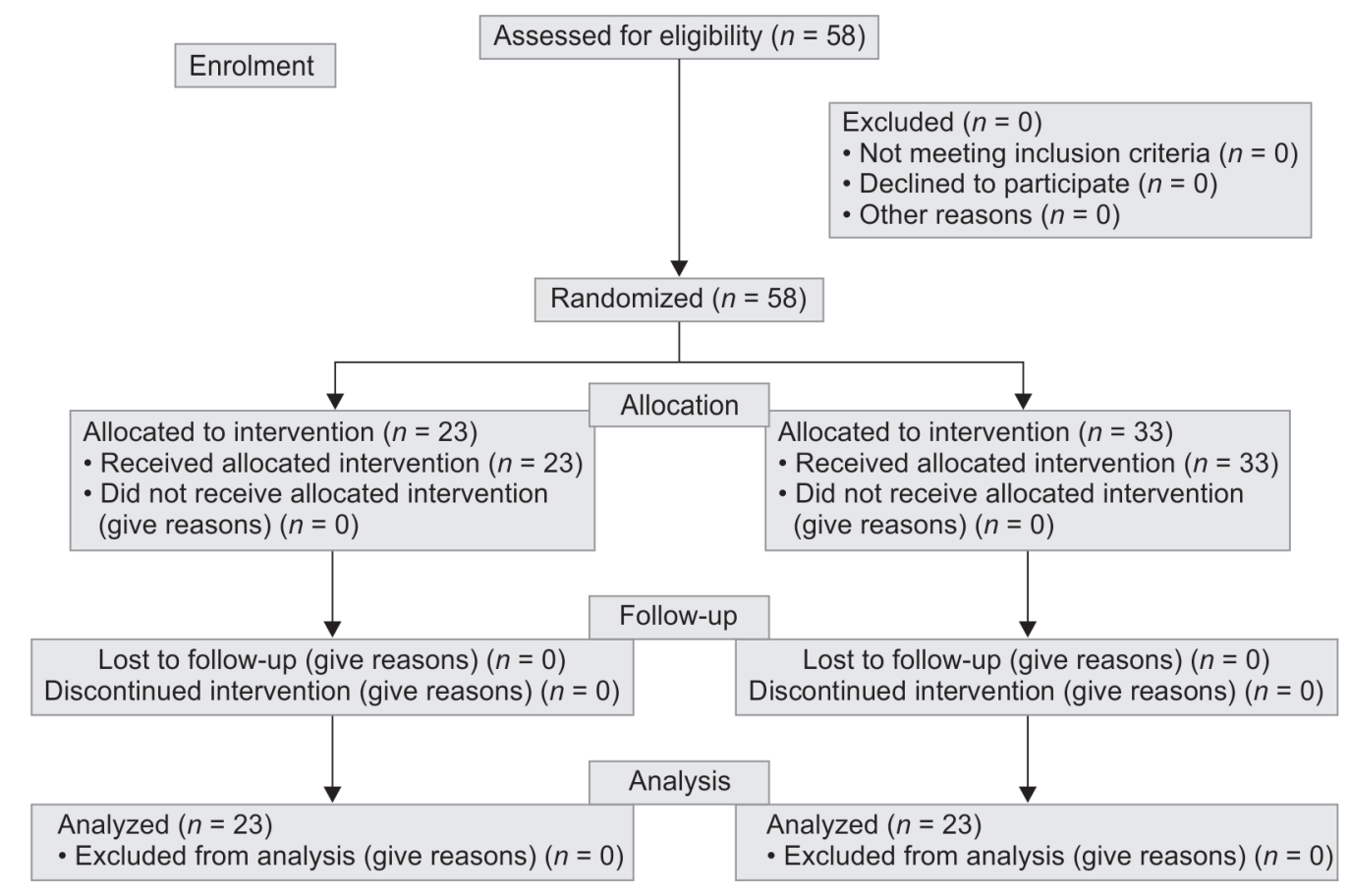

Table 1: Comparison of demographic and clinical characteristics of patients in control and trial groups

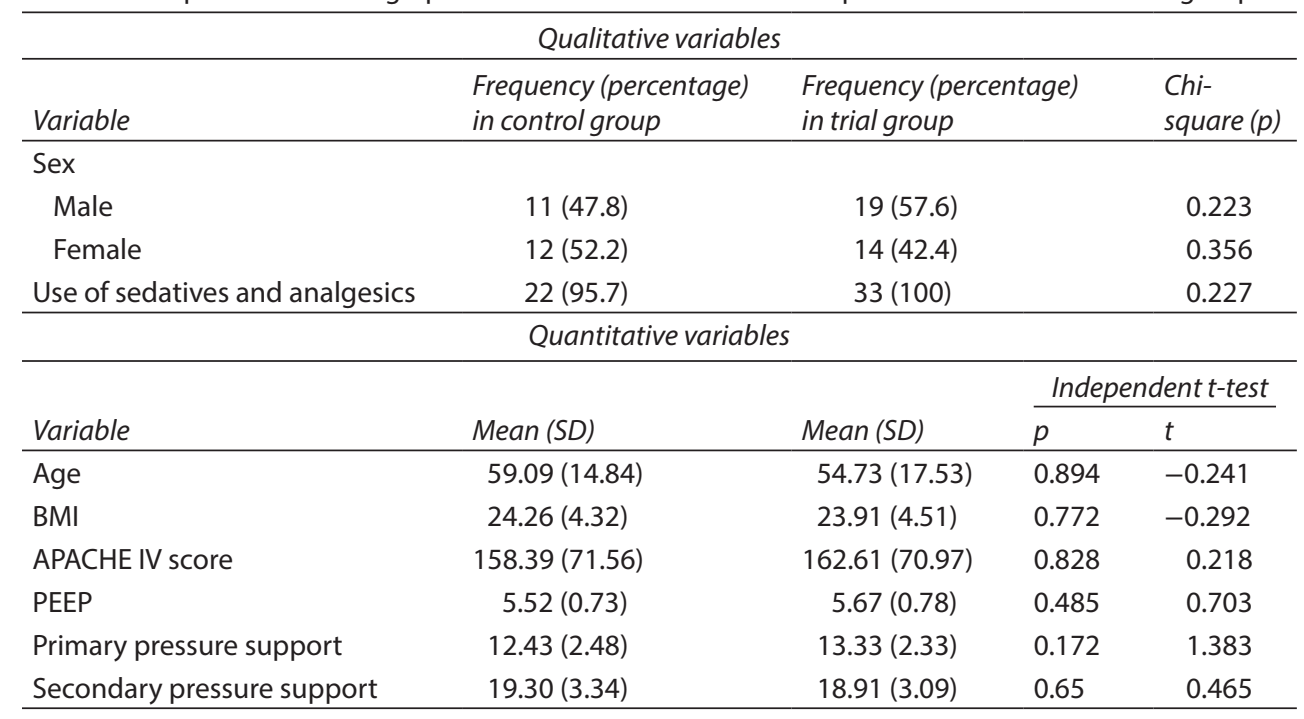

Table 2: Comparison of RSBI and RDOS between two groups before and 15 and 30 minutes after pressure support adjustment

\begin{tabular}{|c|c|c|c|c|}
\hline \multirow[b]{2}{*}{ Variable } & \multirow{2}{*}{$\frac{\text { Control group }}{\text { Mean (SD) }}$} & \multirow{2}{*}{$\frac{\text { Trial group }}{\text { Mean (SD) }}$} & \multicolumn{2}{|c|}{ Independent t test } \\
\hline & & & $p$ & $t$ \\
\hline RSBI before adjustment & $117.43(15.23)$ & $114.33(10.70)$ & 0.374 & -0.896 \\
\hline RSBI 15 minutes after adjustment & $78.39(10.22)$ & $71.61(11.28)$ & 0.025 & -2.3 \\
\hline RSBI 30 minutes after adjustment & $66.39(11.23)$ & $60.91(12.80)$ & 0.103 & -1.657 \\
\hline RDOS before adjustment & $6.17(2.66)$ & $6.2(2.58)$ & 0.657 & -0.446 \\
\hline RDOS 15 minutes after adjustment & $5.97(2.44)$ & $3.01(1.69)$ & 0.044 & -1.787 \\
\hline RDOS 30 minutes after adjustment & $3.11(1.39)$ & $2.39(1.30)$ & 0.218 & -1.09 \\
\hline
\end{tabular}


Comparison of Pressure Support Adjustment Methods

Table 3: Comparison of RDOS between the groups before, 15, and 30 minutes after setting the pressure support

\begin{tabular}{|c|c|c|c|c|c|c|c|}
\hline Source & Time & $\begin{array}{l}\text { Type III sum of } \\
\text { squares }\end{array}$ & $d f$ & Mean square & $F$ & Sig. & $\begin{array}{l}\text { Partial eta } \\
\text { squared }\end{array}$ \\
\hline \multirow[t]{2}{*}{ Time } & Linear & 370.621 & 1 & 370.621 & 154.189 & 0.000 & 0.741 \\
\hline & Quadratic & 7.370 & 1 & 7.370 & 9.093 & 0.004 & 0.144 \\
\hline \multirow[t]{2}{*}{ Time ${ }^{*}$ group } & Linear & 4.193 & 1 & 4.193 & 1.744 & 0.192 & 0.031 \\
\hline & Quadratic & 3.728 & 1 & 3.728 & 4.599 & 0.037 & 0.078 \\
\hline \multirow[t]{2}{*}{ Error (time) } & Linear & 129.798 & 54 & 2.404 & & & \\
\hline & Quadratic & 43.769 & 54 & 0.811 & & & \\
\hline
\end{tabular}

Table 4: Comparison of RSBI between the groups before, 15, and 30 minutes after setting the pressure support

\begin{tabular}{|c|c|c|c|c|c|c|c|}
\hline Source & Time & $\begin{array}{l}\text { Type III sum of } \\
\text { squares }\end{array}$ & $d f$ & Mean square & $F$ & Sig. & Partial eta squared \\
\hline \multirow[t]{2}{*}{ Time } & Linear & 73958.483 & 1 & 73958.483 & 766.776 & 0.000 & 0.934 \\
\hline & Quadratic & 7883.009 & 1 & 7883.009 & 172.482 & 0.000 & 0.762 \\
\hline \multirow[t]{2}{*}{ Time * group } & Linear & 38.411 & 1 & 38.411 & 0.398 & 0.531 & 0.007 \\
\hline & Quadratic & 56.176 & 1 & 56.176 & 1.229 & 0.272 & 0.022 \\
\hline \multirow[t]{2}{*}{ Error (time) } & Linear & 5208.509 & 54 & 96.454 & & & \\
\hline & Quadratic & 2467.988 & 54 & 45.703 & & & \\
\hline
\end{tabular}

after adjusting the pressure support. In other words, these two methods finally (30 minutes after adjusting the pressure support) reduced the patients' respiratory distress almost equally, but in the first 15 minutes after adjusting the pressure support, the RSBI adjustment method decreased patient's respiratory distress further than the conventional method; thus, adjusting pressure support using the RSBI method seems to relieve symptoms of respiratory distress faster than when the conventional method is used. As a result, the application of RSBI for adjusting pressure support may be more accurate than the conventional method.

This finding is also confirmed by the results of a study conducted by Johannigman et al. on the relationship of WOB with $\mathrm{RR}, \mathrm{RSBI}$, and other respiratory pattern variables. The cited study was conducted on 15 patients under treatment with pressure support ventilation admitted to the ICU. The results showed a strong relationship between RSBI and the WOB measured by an invasive method $(r=0.983)$, but RR alone was also related to WOB $(r=0.894)$, although the severity of this relationship was less than that of RSBI. ${ }^{17}$ In other words, according to the results of the study, RSBI is a parameter that is most related to WOB, and the index is thus probably a more accurate method for adjusting pressure support than using the RR.

According to the results obtained by Alberti et al., the correlation between WOB and RR is not so strong. The aim of that study was to assess the effect of using respiratory pattern variations, P0.1, and WOB on the correct adjustment of pressure support in mechanically ventilated patients. Their samples consisted of 10 patients with respiratory failure. In their study, the patients' pressure support was adjusted to PS 100 at first (a level of pressure support in which P0.1 is less than 1.5 centimeter of water and the WOB is close to $0 \mathrm{~J} / \mathrm{L}$ ) and was then reduced to PS 85 (a level of pressure support that is $85 \%$ of PS 100), PS 70, and PS 50. The RR, VT, RSBI, P0.1, and WOB were measured as pressure support was being decreased.
Based on the results, a significant positive relationship was observed between P0.1 and WOB ( $r=0.87)$. There was also a relatively strong relationship between RR and WOB, although weaker than the relationship between WOB and P0.1 $(r=0.53)$. These results generally show that in patients under pressure support ventilation, P0.1 is probably a more sensitive parameter for adjusting pressure support compared to RR and VT. ${ }^{9}$

The results of a study conducted by Banner et al. to determine the relationship between respiratory pattern variables and WOB showed that the relationship between all these variables and WOB was weak. The cited study was carried out on 67 patients treated with pressure support ventilation. The results showed a slight relationship between these variables and WOB. These results suggest that it is better not to use changes in respiratory pattern variables for adjusting pressure support and that the measurement of WOB is preferred for adjusting pressure support. ${ }^{20}$

Some studies have shown that using respiratory pattern variables is not a proper way for adjusting pressure support. Nonetheless, the results of some studies reject the inefficiency of respiratory pattern variables in adjusting pressure support and propose the measurement of RSBI as a possibly proper method of adjusting pressure support. Very few studies have been conducted in this field; therefore, further studies with larger sample sizes are required.

Bennet 840, Hamilton C2, Hamilton C3, Hamilton Raphael, and Bellavista ventilators were available in the ICU of the research environment. Some of them have internal flow sensors and some others have external flow sensors; therefore, their accuracy in displaying patients' data is different, but due to the limited number of ventilators, it was not possible to use one model of the ventilator (limitation of the study), but all flow sensors were calibrated before the intervention. The findings of this study can be used for future research to find the best method of adjusting pressure support to reduce patients' respiratory distress more and faster. 


\section{Conclusion}

VT, RR, and RSBI methods finally reduced the patients' respiratory distress almost equally, but patients' respiratory distress was decreased more significantly in the first 15 minutes after adjusting the pressure support in RSBI group compared to the VT and RR group. Therefore, adjusting pressure support based on the RSBI reduced patients' respiratory distress faster than the conventional method. In other words, RSBI may be a more accurate method for pressure support adjustment than the conventional method.

\section{ACKnOWLedgments}

The authors wish to express their appreciation to the Research Deputy of Isfahan University of Medical Sciences (project number: 3981037, IR.MUI.RESEARCH.REC.1399.040) and all patients and their families for their cooperation in the study.

Registration number: The study was approved by the School of Nursing and Midwifery of Isfahan University of Medical Sciences that was registered with Iranian Registry of Clinical Trials (IRCT20200429047242N1). It was also registered with the Research Ethics Committee (Code: IR.MUI.RESEARCH.REC.1399.040).

\section{OrCID}

Pooneh Barati @ https://orcid.org/0000-0002-1625-0501

Somayeh Ghafari $\odot$ https://orcid.org/0000-0001-9331-0902

Mahmood Saghaei i https://orcid.org/0000-0002-8766-8139

\section{References}

1. Criner G. Long-term ventilator-dependent patients: new facilities and new models of care: the American perspective. Rev Port Pneumol 2012;18(5):214-216. DOI: 10.1016/j.rppneu.2012.04.004.

2. Youssef HAA, Shalaby AEO, Abd El Hafiz AM, Shaban MM, Hamed HA. Predictive value of rapid shallow breathing index in relation to the weaning outcome in ICU patients. Egypt J Chest Dis Tuberc 2016;65(2):465-472. DOI: 10.1016/S0929-6646(09)60135-2.

3. Urden LD, Stacy KM, Lough ME. Critical care nursing-e-book: diagnosis and management. Elsevier Health Sciences; 2017.

4. Thille AW, Rodriguez P, Cabello B, Lellouche F, Brochard L. Patientventilator asynchrony during assisted mechanical ventilation. Intensive Care Med 2006;32(10):1515-1522. DOI: 10.1007/s00134-006-0301-8.

5. Campbell ML, Templin TN. Intensity cut-points for the respiratory distress observation scale. Palliat Med 2015;29(5):436-442. DOI: 10.1177/0269216314564238.

6. Ambrosino N, Vitacca M. The patient needing prolonged mechanical ventilation: a narrative review. Multidiscip Respir Med 2018;13. DOI: 10.1186/s40248-018-0118-7.

7. Elliott S, Morrell-Scott N. Care of patients undergoing weaning from mechanical ventilation in critical care. Nurs Stand 2017;32(13):41-51. DOI: 10.7748/ns.2017.e10854.
8. Desai JP, Moustarah F. Pulmonary compliance. StatPearls [Internet] StatPearls Publishing; 2019.

9. Alberti A, Gallo F, Fongaro A, Valenti S, Rossi A. P0.1 is a useful parameter in setting the level of pressure support ventilation. Intensive Care Med 1995;21(7):547-553. DOI: 10.1007/BF01700158.

10. Perrigault PF, Pouzeratte $Y H$, Jaber S, Capdevila XJ, Hayot M, Boccara G, et al. Changes in occlusion pressure (P0.1) and breathing pattern during pressure support ventilation. Thorax 1999;54(2):119-123. DOI: 10.1136/thx.54.2.119.

11. Vincent J-L, Abraham E, Kochanek P, Moore FA, Fink MP. Textbook of critical care e-book. Elsevier Health Sciences; 2016.

12. Morton PG, Fontaine DK, Hudak C, Gallo B. Critical care nursing: a holistic approach. Lippincott Williams \& Wilkins Philadelphia; 2005.

13. Elliott D, Aitken L, Chaboyer W. Critical care nursing. Sydney: Mosby Elsevier; 2007. p. 448-453.

14. Marino PL. The ICU book. 4th ed. Philadelphia:Wolters Kluwer Health/ Lippincott Williams \& Wilkins; 2014. 1059 p.

15. Esteban A, Frutos F, Tobin MJ, Alía I, Solsona JF, Valverdú I, et al. A comparison of four methods of weaning patients from mechanical ventilation. Spanish Lung Failure Collaborative Group. N Engl J Med 1995;332(6):345-350. DOI: 10.1056/NEJM199502093320601.

16. Cairo JM. Pilbeam's mechanical ventilation. St. Louis, Missouri: Elsevier; 2016.

17. Johannigman JA, Davis K, Campbell RS, Branson RD, Luchette FA, Hurst JM. Use of the rapid shallow breathing index as an indicator of patient work of breathing during pressure support ventilation. Surgery 1997;122(4):737-740. DOI: 10.1016/s0039-6060(97)90081-7.

18. Soleimanpour $\mathrm{H}$, Taghizadieh A, Salimi R, GolzariSE, Mahmoodpoor A, Safari S, et al. Rapid shallow breathing index survey, a predictor of non-invasive ventilation necessity in patients with chronic obstructive pulmonary disease exacerbation: an analytical descriptive prospective study. Iran Red Crescent Med J 2014;16(2):e13326. DOI: 10.5812/ircmj.13326.

19. Aliverti A, Carlesso E, Dellacà R, Pelosi P, Chiumello D, Pedotti A, et al. Chest wall mechanics during pressure support ventilation. Crit Care 2006;10(2):R54. DOI: 10.1186/cc4867.

20. Banner MJ, Kirby RR, Kirton OC, DeHaven CB, Blanch PB. Breathing frequency and pattern are poor predictors of work of breathing in patients receiving pressure support ventilation. Chest 1995;108(5):13381344. DOI: $10.1378 /$ chest.108.5.1338.

21. Gonçalves EC, Silva EC, Basile Filho A, Auxiliadora-Martins M, Nicolini EA, Gastaldi AC. Low pressure support changes the rapid shallow breathing index (RSBI) in critically ill patients on mechanical ventilation. Rev Bras Fisioter 2012;16(5):368-374. DOI: 10.1590/s141335552012005000037.

22. Guo L, Wang W, Zhao N, Guo L, Chi C, Hou W, et al. Mechanical ventilation strategies for intensive care unit patients without acute lung injury or acute respiratory distress syndrome: a systematic review and network meta-analysis. Crit Care 2016;20(1):226. DOI: 10.1186/s13054-016-1396-0.

23. Campbell ML, Templin T, Walch J. A respiratory distress observation scale for patients unable to self-report dyspnea. J Palliat Med 2010;13(3):285-290. DOI: 10.1089/jpm.2009.0229. 